\title{
Cognitive function in Familial Adenomatous Polyposis: anyone out there listening?
}

\author{
Margaret O’Malley ${ }^{1 *}$, Lisa LaGuardia”, Richard Naugle ${ }^{2}$, Cynthia Gensur $^{4}$, Jeff Hammel ${ }^{4}$, James Church', \\ Carol Burke ${ }^{3}$ \\ From 13th Annual Meeting of the Collaborative Group of the Americas on Inherited Colorectal Cancer \\ Honolulu, Hawaii, USA. 16-17 October 2009
}

\section{Background}

Preliminary data suggests the APC protein is critical for dependent pathways in the cochlea and may be important in cognition. Abnormal audiometries have been documented in Familial Adenomatous Polyposis (FAP). We studied cognitive function among patients with FAP.

\section{Methods}

FAP patients were recruited for an IRB (Institutional Review Board) approved study assessing intelligence using the Kaufman Brief Intelligence Test (KBIT-2), which provides Verbal, Nonverbal and Composite IQs. The KBIT-2 was administered and scored by individuals experienced in administration of psychometric measures. Mean scores were analyzed and compared to standard normal ranges.

\section{Results}

44 subjects from 42 families ( 22 men), mean age of 42 years were included. KBIT-2 Composite IQ score was 98.4 \pm 12.4 , (95\% CI (confidence interval) 94.5-102.3) which is within the average range of 90-109. $27 \%$ of patients scored below average (less than 90) and 15\% scored above average (greater than 109), not a significant imbalance (sign test $\mathrm{p}=0.33$ ). Nonverbal IQ scores show no difference from average, mean $=100.5 ; 24 \%$ scored below and $27 \%$ scored above average. Verbal scores were $95.5 \pm 12.0$ (95\% CI 91.7 -99.2) significantly lower than average (one-sample T-test $\mathrm{p}=0.020$ ). There is an imbalance among patients with $27 \%$ below and $7 \%$ above the average range and a tendency toward lower than average scores (sign test $\mathrm{P}=0.06)$. The mean number of points by which Nonverbal IQ exceeded Verbal IQ was $5.0 \pm 12.5$ (95\% CI 1.1 -9.0), (one-sample $\mathrm{T}$-test $\mathrm{p}=0.013)$. The non-verbal score exceeded the verbal score for 27 patients (65.9\%), while the verbal score was larger for only 10 patients (24.4\%) (Sign test $\mathrm{p}=0.008)$.

\section{Conclusion}

Composite IQ scores suggest that FAP patients do not have lower IQ from the general population. However the verbal scores of FAP patients which are dependent on hearing are significantly lower than average and may reflect abnormal audiometries or other effects of the APC mutation on cognitive function.

\begin{abstract}
Author details
${ }^{1}$ Sanford R. Weiss, M.D. Center for Hereditary Colorectal Neoplasia, Department of Colorectal Surgery, Cleveland Clinic, Cleveland, Ohio 44195, USA. ${ }^{2}$ Sanford R. Weiss, M.D. Center for Hereditary Colorectal Neoplasia, Department of Psychiatry and Psychology, Cleveland Clinic, Cleveland, Ohio 44195, USA. ${ }^{3}$ Sanford R. Weiss, M.D. Center for Hereditary Colorectal Neoplasia, Department of Gastroenterology, Cleveland Clinic, Cleveland, Ohio 44195, USA. ${ }^{4}$ Sanford R. Weiss, M.D. Center for Hereditary Colorectal Neoplasia, Department of Audiology, Cleveland Clinic, Cleveland, Ohio 44195, USA

Published: 25 May 2010

doi:10.1186/1897-4287-8-S1-P15

Cite this article as: O'Malley et al:: Cognitive function in Familial

Adenomatous Polyposis: anyone out there listening? Hereditary Cancer in Clinical Practice 2010 8(Suppl 1):P15.
\end{abstract}

\footnotetext{
* Correspondence: omallem@ccf.org

'Sanford R. Weiss, M.D. Center for Hereditary Colorectal Neoplasia,

Department of Colorectal Surgery, Cleveland Clinic, Cleveland, Ohio 44195,
} USA 